\title{
Ethics and "Pembelajaran Matematika Realistik Indonesia" (PMRI): a Critical Reflection on Mathematics Instruction Practice
}

\author{
M.M. Simanjorang, S. Gultom \& B. Sinaga \\ Science and Mathematics Departement \\ Universitas Negeri Medan \\ Medan, Indonesia \\ mangaratuasimanjorang@gmail.com
}

\begin{abstract}
The emphasize on character education in Indonesian national education policy includes the concern of ethical value. As part of the national education system, mathematics education should also have a concern on ethical values. However, many experts believe that mathematics is free value and has nothing to do with this value domain. As a response to this view, authors have done a study on integrating ethical values into mathematics instruction. By using a philosophical auto/ ethnographic methodology and employing narrative inquiry method, the study showed that it is possible to integrate ethics and mathematics instruction especially Pembelajaran Matematika Realistik Indonesia (PMRI). Considering the characteristics of PMRI, it is possible to integrate ethics through the realistic problem, open problem, interactivity, and reflection.
\end{abstract}

Keywords; Ethics, PMRI, Mathematics

\section{INTRODUCTION}

Different standpoints may provide different views. A person who is sitting in a vehicle may see that other objects outside the vehicle are moving toward the opposite direction of the vehicle. Meanwhile, a person who is looking at the vehicle from the side of the road may see that it is the vehicle, which moves while other objects stay still in their positions. Differences in the educational, economical, beliefs, cultural or social background may be the reasons behind the differences in these standpoints. Hence, the different points of views are naturally and easily found in society, which has high diversity.

Differences may bring harmony in life but also may become the source of conflict, depend on how society member respond to differences. The ability to respond to differences wisely will help to avoid conflict. This response ability plays an important role in creating a harmonious life. Hence, how one responds to differences will determine one's relationships with others. The concern of one's responses towards others brings forward consideration on ethics. Ethics is born when we are encountering the other. By encountering another person, one faces another existence that brings along similarities and differences. In this face-to-face encountering moment, one is called to respond to this unique existence. This moment when one is called, before the response, is when ethics is born.

The ethical concern in a relationship with others, especially in society with high diversity, has an important role to avoid conflict and to bring harmonious life. Education may help to cultivate this concern. Indonesian current educational system opens a big opportunity in this domain by emphasizing character education. This educational policy places big concern on cultivating ethical values through education. However, it is not so easy for each subject.

\section{METHOD}

This article reveals some of the results from a study that focuses on understanding the opportunity to integrate ethics into mathematics instruction. In order to be able to understand this focus, the study used multiparadigmatic approach. There were three paradigms that influenced the study, which are critical theory, interpretivism, and postmodernism. Integration of these three paradigms gave birth to a methodology called philosophical auto/ ethnographic research (Simanjorang, 2016). Under the influence of interpretivism paradigm, researchers construct meaning and understand it by actively interpret their experiences (Taylor, et al., 2012). Through this way, the context and the subjects who interpret the experiences cannot be separated from the meaning that was being constructed. The critical theory allows researchers to be aware of a set of values and beliefs that shaped all practices they have so far and then develop a better practice (Taylor, 2008). Postmodernism allowed researchers to use different logic including a wide range of arts based representation (Taylor, et al., 2012). In line with the methodology, researchers chose critical narrative inquiry as a way to represent and a method to study the experiences in the study. Through this method, researchers combined the data gathered from the study and their personal experiences.

\section{RESULT AND DISCUSSION}

\section{A. Different view on ethics}

Ethics is an ancient terminology that has been used since ancient Greek era. The effort on answering Socrates' question 
'how one should live' (William, 2006; Ahbel-Rappe \& Kamtekar, 2009) has emerged various concepts of ethics. Ethics of virtue, utilitarian ethics, and ethics of duty are some major views on ethics. Ethics of virtue tried to answer Socrates question based on individual character, while the other two tried to answer based one's actions. That is why they are also known consecutively as ethics of character and ethics of action (Hinman, 2008). These three views connect ethics with the concept of good or bad. According to ethics of virtue, one may become good and perform well if virtue character exists in oneself (Crisp, 2004). Utilitarian ethics sees one's action as a good action based on the consequence(s) of the action (Hinman, 2008). If one's action results in a good state of the affair then the action is considered as a good one. While the ethics of duty emphasized three pillars: (1) doing a right thing is one's duty, (2) an action is considered good if it is accepted good by others in similar situation and (3) the action represents respect towards other individual (Hinman, 2008).

There are also a lot of different concepts of ethics other than these three views, which approach ethics, not from good or bad concepts. One of them is ethics of encounter that was introduced by Levinas (Chritchley, 1999). The question how one should live might be asked in consideration of the existence of the other. One needs to think about one's attitude and action in response to the existence of others. One's is called to think and act ethically when encountering the others. The existence of other is not something that is created by someone, and one's understanding of other is not necessarily equal to the real other. Simply said that, it is impossible for someone to grasp the other totally. When one person claims that the person understands other usually means that the person understands other's part. In other words, the person reducing the other into a state that may be grasped by the person. Ethics according to Levinas is a place where other is placed in its exteriority without being reduced to one's understanding (Chritchley, 1999). This view emphasizes that instead of reducing, one should welcome other as other self. It is clear that this view does not approach ethics from good or bad, instead approaches ethics from one's relationship with other. Different concepts of ethics show the limit of one view on ethics. Hence, more views are needed to understand ethics better (William, 2006) rather than choosing one view. In this study, ethics is about one's response ability to the existence of the other. Under the influence of three different paradigms explained before, ethical consideration is related to the particularity of context where the response is taken instead of trying to generalize what ethical character or action is.

\section{B. Values in mathematics}

As mentioned above, experts claim that there is no relationship between mathematics and value. However, there are also many literatures that emphasized the existence of values in mathematics.

What someone learns usually influences one's way of thinking. An economist will likely respond in a different way to a particular problem compared with how an engineering or a scientist respond to the same problem, since characteristics of the discipline they learned influenced their way of thinking. In mathematics, this influence on the way of thinking may be called as thinking mathematically. Soedjadi (Gijse, 2010) said that in real life one person most likely uses mathematical thinking instead of mathematical skill. This is where mathematical values may be traced obviously since it is unique to mathematics influence. This mathematical thinking is based on mathematical characteristics then the values of mathematics may be found in its characteristics. One of the mathematics characteristics is that mathematics considers highly the existence of the universe in every mathematical problem (Swadener \& Soedjadi, 1988). In other word, truth in mathematics is based on its system. $1+12=13$ is true in whole number system but in clock system $1+12=1$ since 1 hour after 12 o'clock is 1 o'clock. Therefore, what is the value expressed by this mathematical universe characteristic?

People from different cultural background may have a different view about manner. In one society, it may be proper to shake other's hand hardly on shaking hand moment while in other society it may be seen as the rude thing to do. In one society, talking about different gender in public may be seen as normal while in other society it may be seen improper. The ability to respect the universe in mathematics may be used to cultivate respect for differences in real life. The problem is that practices in mathematics class rarely uncovered this potential value. If mathematics education is designed by uncovering this value, then it is possible to cultivate such values through experiences in learning mathematics. By learning, that truth may be different according to its universe. Mathematics students may learn to respect different views in real life. Students may learn to seek the truth behind differences instead of judging whether one's view is true or false. This is one example of values in mathematics characteristics while there are other values that need to be discovered from mathematics characteristics.

\section{Ethics in PMRI}

PMRI (Pembelajaran Matematika Realistik Indonesia) is adopted from Realistic Mathematics Education by considering Indonesian local culture. Thus, this cultural aspect distinguishes PMRI from RME (de Haan, et al. 2010). The feudhental view is that mathematics is a human activity that has to be connected to the real world (Gravemaijer, 1994) and become foundation of PMRI. Based on this view, students need to reinvent mathematics concepts with guidance from the teacher. This guided reinvention process should be related to students real life. Hence, the usage of realistic problems is essential in this approach. Realistic in PMRI does not literally mean the object of real life but something that is real in students' mind. In other words, mathematical objects, which are abstract, such as line, mathematical concepts or operations may be accepted as real when students see them as real in their mind. In other words, along with students' growth, there will be other real things in students' mind.

There are three underlying principles of PMRI, which are: (1) guided reinvention through progressive mathematizing, (2) didactical phenomenology and (3) self-developed model. The first principle emphasizes the process of guided reinvention through the process of solving a realistic problem. Based on this principle, students may construct formal mathematical knowledge when the students are able to move from the 
realistic world into the world of symbol and moving in this world of the symbol. Providing proper guide is an essential role of the teacher in this process. The second principle emphasizes the importance of choosing or designing realistic problems that have potential in generating formal mathematical knowledge. Routine problems that emphasize procedural knowledge most likely do not suite this principle. The third principle emphasizes the use of students' own model in solving the problem. This principle reflects Freudenthal's view that mathematics is a human's activity.

From these principles then derives PMRI characteristics, which include the use of contexts, the use of models, the use of students' contributions, inter-activity and intertwining. Critical reflection on this principles and characteristics in this study results in the identification of some aspects in PMRI that provide an opportunity to integrate ethics into mathematics instruction, they are a realistic problem, open problem, interactivity, and reflection.

\section{Realistic problem}

Realistic problem is one of PMRI characteristics as indicated by its name. This characteristic connects the mathematics classroom to students' life. The closer the problem to students' experiences the more it triggers their feeling and imagination (Simanjorang, 2016). Hence, when this kind of problem includes a concern on ethics, the better it may raise students' ethical consideration. Appropriate questions chosen by the teacher, in this case, might play as a guide to ethical responsibility consideration.

2. Open problem

Open problem allows students to choose different strategies or various correct answers. "By exposing the students to different answers, each of which is true, they learn to open their eyes to the possibility of finding different solutions to a problem" (Simanjorang, 2016: 118). Being put in a situation where students may see that there are various true answers may help the students to broaden their view. Instead of stuck with the single correct answer, they might be aware of another possible correct one. Consistently learning in this kind of learning environment may encourage the students "to think critically in diverse circumstances, to check truth or value from different viewpoints, and to reflect critically on their individual points of view" (Simanjorang, 2016: 118).

\section{Interactivity}

Interactivity provides an opportunity for students to encounter others. Since ethics is born in the moment of encountering the other then interaction plays a big role to provide this moment. By having an opportunity to interact with other, students experienced the existence of the unique other. Aware of other's uniqueness may help to strengthen self-awareness as well. In other words, "interactions with others that provides this opportunity may help us to understand better ourselves and others, which may improve our ability to respond to the other more ethically" (Simanjorang, 2016: 122).

\section{Reflection}

Reflection is a conscious consideration of one's experiences through which one may establish a relationship between ideas or actions (Hiebert in Nelissen, 1999). By bringing reflection into the classroom, students are invited to consciously reconsider their learning experiences. "This opportunity will be the best moment for students to reflect on any values they have learned, and to internalize them. This step may amplify what they have just learned" (Simanjorang, 2016: 125).

\section{CONCLUSION}

Ethical values should not be taught merely by a particular subject, but cultivated through experiences in the learning environment. The possibility of integrating ethical values into mathematics education comes from two aspects, which are mathematics characteristics and pedagogy used in teaching mathematics. PMRI's characteristics allow such a learning environment occurred. PMRI provided an environment which allows students experience and live the ethical values. Through such environment, students have an opportunity to cultivate ethical values. As discussed earlier, there are four aspects of PMRI that can be used to integrate ethical values into mathematics education; they are (1) realistic problem, (2) open problem, (3) interactivity, and (4) reflection. Of course, they do not exclusively belong to PMRI. In other words, any educational approach, which has these aspects, may use them to integrate ethics in mathematics instruction. It is possible to find other aspects in mathematics education that provide opportunities to integrate ethics into mathematics education. Further studies will be needed in order to find those other aspects. Hence, authors encourage readers and fellow researchers to study further in this area of interest.

\section{REFERENCES}

[1] Ahbel-Rappe, S., \& Kamtekar, R. 2009. A companion to Soc-rates. Sussex: Willey Blackwell.

[2] Bishop, A. J. 2008. Mathematics teaching and values educa-tion: An intersection in need of research. In P. Clarkson \& N. Presmeg (Eds.), Critical issues in mathematics education (pp. 231-238). New York: Springer.

[3] Connelly, F. M., \& Clandinin, D. J. 1990. Stories of experience and narrative inquiry. Educational Researcher, 19(5), 2-14.

[4] Crisp, R. 2004. Aristotle: Nicomachean ethics. Cambridge: Cambridge University Press.

[5] Critchley, S. 1999. The ethics of deconstruction: Derrida and Levinas (2nd ed). Edinburgh: Edinburgh University Press.

[6] De Haan, D., Meiliasari, \& Sari, P. 2010. Local workshops in PMRI: Learning from experiences. In R. Sembiring, K. Hoogland \& M. Dolk (Eds.), A decade of PMRI in Indone-sia (pp.131-152). Utrecht: Ten Brink.

[7] Egea-Kuehne, D. 2008. Levinas and education: At the inter-section of faith and reason. New York: Routledge.

[8] Gijse, A. 2010. Towards a democratic future: Interview with six founding fathers. in R. Sembiring, K. Hoogland \& M. Dolk (Eds.), A Decade of PMRI in Indonesia. Utrecht: Ten Brink

[9] Gravemeijer, K. 1994. Developing realistic mathematics edu-cation. Utrecht: Freudenthal Institute. 
[10] Hinman, L. M. 2008. Ethics: A pluralistic approach to moral theory (4th ed). United States: Thomson Wadsworth.

[11] Nelissen, J.M.C. 1999. Thinking skills in realistic mathematics. Retrieved from http://www.fi.uu.nl/publicaties/literatuur/ 6259.pdf.

[12] Simanjorang, M. 2016. Integrating ethics into mathematics education: A philosophical auto/ethnographic inquiry in-to Indonesian mathematics education. (Doctoral Thesis).Murdoch University, Murdoch, West Australia, Australia.

[13] Swadener, M. \& Soedjadi, R. 1988. Values, mathematics edu-cation, and the task of developing pupils' personalities: An Indonesianperspective. Educational Studies in Mathemat-ics, 19(2), 193208.
[14] Taylor, P. C. 2008. Multi-paradigmatic research design spaces for cultural studies researchers embodying postcolonial theorising. Cultural Studies in Science Education, 4(3), 881-889.

[15] Taylor, P. C., Settelmaier, E., \& Luitel, B. C. 2012. Multi-paradigmatic transformative research as/for teacher edu-cation: An integral perspective. In K. G. Tobin, B. J. Fraser, \& C. McRobbie (Eds.), Second international handbook of science education (pp. 373-387). Dordrecht, The Nether-lands: Springer.

[16] Williams, B. 2006. Ethics and the limits of philosophy. Lon-don: Routledge. 